\title{
OS TRIBUNAIS DE CONTAS DOS ENTES SUBNACIONAIS E O CONTROLE EXTERNO DO ENDIVIDAMENTO PúBLICO
}

\author{
Carlos Richelle Soares da Silva \\ Aluno especial vinculado ao Programa de Pós-Graduação em Direito, \\ da Faculdade de Direito da Universidade de São Paulo (USP), \\ na área de concentração de Direito Econômico, Financeiro e Tributário. \\ Artigo apresentado como avaliação final da disciplina de Dívida Pública. \\ (DEF 5825/17), ministrada pelo Professor Doutor José Mauricio Conti. \\ Especialista em Direito Constitucional pela Uniderp/Anhanguera. \\ Bacharel em Direito pela Universidade Federal do Ceará (UFC). \\ Advogado. Auditor do Tribunal de Contas \\ do Município de São Paulo.
}

\footnotetext{
Introdução - 1. O endividamento público dos entes subnacionais no Brasil: 1.1 Os programas de reestruturação fiscal e financeira no panorama pós-Constituição Federal de 1988; 1.2 As normas que versam sobre os limites do endividamento público versam sobre o seu controle externo - 2. Os Tribunais de Contas dos entes da Federação e o efetivo exercício do controle externo do endividamento público: 2.1 As competências constitucionais e legais dos Tribunais de Contas dos entes subnacionais; 2.2 As normas que balizam o exercício do controle externo do endividamento público - Considerações finais Referências.
} 


\section{INTRODUÇÃO}

Na República Federativa do Brasil, o endividamento público se sobressai como um instrumento constitucional e legal de política financeira, utilizado, entre outras funções governamentais ${ }^{1}$, para garantir níveis equilibrados de investimentos e de serviços prestados pelo governo à sociedade, bem como mecanismo de condução da política monetária, consubstanciando-se, quando bem gerido, em um importante elemento para a manutenção da estabilidade social e econômica.

Quando se estuda a sistemática da formação da dívida pública interna brasileira, é preciso compreender, de antemão, que a capacidade de se valer de um crédito público ${ }^{2}$ para realizar uma operação de crédito $^{3}$ é conferida não só ao governo central (União), como também aos entes subnacionais (Estados e Municípios), dada a autonomia financeira ${ }^{4}$ que constitucionalmente lhes foi atribuída.

Nessa esteira, ao analisar a autonomia das entidades subnacionais e as limitações impostas para o seu endividamento público, discorre o Professor José Mauricio Conti ${ }^{5}$ que "o controle da dívida pública subnacional por parte do go-

1 As funções alocativa, distributiva e estabilizadora devem ser aquelas exercidas pelo setor público para suprir falhas de mercado, segundo uma influente visão normativa das finanças públicas (MUSGRAVE, R.; MUSGRAVE, P. Public Finance in Theory and Practice. Nova Iorque: McGraw Hill, 1980, p. 5-26, apud LOCHAGIN, Gabriel Loretto. Dívida pública: conceito, tipos e natureza jurídica, p. 27 -68. In: LOCHAGIN, Gabriel Loretto. Elementos jurídicos da reestruturação internacional da dívida pública. São Paulo: Blucher, 2017, p. 30).

2 Apoiado na lição de Hector B. Villegas, citado por Sérgio Assoni Filho, para quem crédito público é "a aptidão política, econômica, jurídica e moral de um Estado para obter dinheiro ou bens em empréstimo; e que o empréstimo público é a operação de crédito concreta mediante a qual o Estado obtém tal dinheiro ou bens; e a dívida pública consiste na obrigação que contrai o Estado com os prestamistas como consequência do empréstimo efetuado (VILLEGAS, Hector B. apud ASSONI FILHO, Sérgio. Empréstimos públicos e sua natureza jurídica. Revista da Faculdade de Direito da Universidade de São Paulo, v. 99, 2004, p. 799.

3 O inciso III do art. 29 da Lei de Responsabilidade Fiscal traz a definição de operação de crédito.

4 Assevera Conti que “a autonomia financeira é de fundamental importância. Não é exagero dizer ser ela quem garante a sobrevivência da federação. Sem recursos para se manter, as entidades federadas estão fadadas ao fracasso. Não poderão exercer as funções que lhe competem, e passarão a depender do poder central para financiar suas atividades, circunstância que aniquila todo e qualquer poder autônomo que se lhes atribua (CONTI, José Mauricio. Dívida pública e responsabilidade fiscal no federalismo brasileiro. In: SCHOUERI, Luís Eduardo (coord.). Direito tributário. Homenagem a Alcides Jorge Costa. São Paulo: Quartier Latin, 2003. v. 2, p. 1082.

5 Cf. CONTI, José Mauricio. Divida pública e responsabilidade fiscal no federalismo brasileiro, cit., p. 1092. 
verno central é medida que tem sido adotada por vários países, sendo visto como modo eficiente para o adequado controle das contas públicas e por uma gestão responsável dos recursos administrados”.

Cesar Augusto Seijas Andrade 6 , buscando ressaltar a relevância do aspecto finalístico do controle da dívida pública, afirma que "é matéria de relevância nacional, pois o endividamento elevado dos entes subnacionais causa impacto na estabilidade econômica do País, obrigando o governo central, em situações extremas, a intervir e assumir a dívida dos entes subnacionais".

Nesse contexto, a formação, a fiscalização e a gestão da dívida pública dos entes subnacionais mostram-se mais complexas diante da dinâmica das relações jurídicas e institucionais que se estabelecem entre eles e o governo central, demandando a atuação administrativa conjunta e/ou isolada de diversos órgãos de controle constitucionalmente instituídos, pertencentes às três esferas políticas (União, Estados e Municípios) e aos três poderes (Executivo, Legislativo e Judiciário).

No decorrer deste trabalho, restará evidenciado que o Brasil adota como métodos de controle do endividamento público a edição de normas jurídicas ( $r u$ led-based approaches ${ }^{7}$ ) e a manutenção de um controle administrativo (administrative control ${ }^{8}$.

A CF/88, a Lei de Responsabilidade Fiscal (LRF) e as Resoluções do Senado Federal (RSF) n. 40, de 20 de dezembro de 2001, e n. 43, de 21 de dezembro de 2001, são os diplomas que atualmente veiculam as regras para o endividamento público dos entes subnacionais, enquanto o controle administrativo fica a cargo de diversos órgãos de accountability, entre os quais, para a análise que aqui se verificará, interessa a função exercida pelos Tribunais de Contas dos Entes Subnacionais.

Conforme disposição expressa do art. 71 da Constituição Federal de 1988 (CF/88), o Tribunal de Contas da União (TCU) é o órgão tecnicamente incumbido de exercer o controle externo da gestão pública, cujas competências estão traçadas especificamente nos arts. 71 a 74 da norma supracitada.

6 Cf. ANDRADE, Cesar Augusto Seijas de. O controle do endividamento público e a autonomia dos entes da federação. Dissertação (Mestrado) - Faculdade de Direito da Universidade de São Paulo, São Paulo, 2012, p. 65.

7 Na classificação proposta por Teresa Ter-Minassian e Jon Craig. Cf. Control of subnational government borrowing. In: TER-MINASSIAN, Teresa (ed.). Fiscal federalism in theory and practice. Washington: International Monetary Fund, 1997, p. 165-167.

8 Cf. TER-MINASSIAN, Teresa; CRAIG, Jon. Control of subnational government borrowing, cit., p. 169. 
No tocante aos Tribunais de Contas dos Estados e dos Municípios, o art. 75 da $\mathrm{CF} / 88$ preceitua que:

As normas estabelecidas nesta seção aplicam-se, no que couber, à organização, composição e fiscalização dos Tribunais de Contas dos Estados e do Distrito Federal, bem como dos Tribunais e Conselhos de Contas dos Municípios.

Parágrafo único. As Constituições estaduais disporão sobre os Tribunais de Contas respectivos, que serão integrados por sete Conselheiros.

Portanto, sob a égide da sistemática constitucional do controle externo brasileiro, os Tribunais de Contas Estaduais e Municipais devem estar previstos e disciplinados nas respectivas Constituições derivadas, exercendo atribuições correlatas às do TCU, circunscritos as suas esferas de atuação. Aplica-se, dessa forma, o princípio da simetria federativa.

Ao observar o rol das competências constitucionais impostas aos Tribunais de Contas (arts. 70 c/c 71, incisos I a XI da CF/88), destaca-se o papel relevante que esses órgãos desempenham, ou pelo menos deveriam desempenhar, na fiscalização da gestão financeira estatal, da qual é indissociável, por determinação legal, o controle externo do endividamento público regulamentado no art. 59, incisos II a IV da Lei Complementar n. 101/2000 (LRF).

Contudo, não obstante a previsão do controle externo do endividamento público, os Estados e os Municípios brasileiros vêm historicamente vivenciando crises financeiras graves, recorrendo, frequentemente, às operações de refinanciamento $\left(\right.$ Bailout $\left.{ }^{9}\right)$ promovidas pelo próprio Governo Central.

O desequilíbrio fiscal histórico e a necessidade de ajuste das contas públicas nos Estados e Municípios demonstram que o controle externo do endividamento público desses entes é ineficiente, ineficaz e não efetivo, quando não inexistente, apesar de devidamente regulamentado na $\mathrm{CF} / 88$ e nas leis.

Por isso, após discorrer brevemente sobre alguns aspectos teóricos do endividamento público dos entes subnacionais, e considerando ainda as informações que serão apresentadas ao longo do artigo, restará induvidosa a relevância material da gestão e do controle da dívida pública.

Pelo exposto, os objetivos deste artigo são, primeiro, buscar evidenciar as competências constitucionais e legais dos Tribunais de Contas dos Estados e dos

9 Isabella Fonte Boa Rosa Silva, citada por Seijas, afirma que bailout refere-se "a qualquer tipo de socorro financeiro, geralmente do governo central, para o pagamento de dívidas dos governos subnacionais não honradas”. Cf. ANDRADE, Cesar Augusto Seijas de. O controle do endividamento público e a autonomia dos entes da federação, cit., p. 64. 
Municípios e a proficiência técnica presente no seu corpo de trabalho, o que os torna órgãos de controle essenciais para a gestão sustentável da dívida pública nacional e subnacional, e, segundo, criticar o pouco e incipiente trabalho técnico no âmbito dessas Cortes de Contas no tocante ao controle prévio, concomitante e a posteriori do endividamento público.

\section{O ENDIVIDAMENTO PÚBLICO DOS ENTES SUBNACIONAIS NO BRASIL}

Centrando-se apenas no aspecto jurídico, esse estudo adota o entendimento de que a natureza da dívida pública dos entes subnacionais incorpora os mesmos elementos, conceitos e classificações da dívida pública federal ${ }^{10}$, diferenciando-se assim apenas na sua feição subjetiva, ou seja, em relação à esfera governamental que está contraindo a dívida.

Traçar uma trajetória da dívida pública dos governos subnacionais e, concomitantemente, analisar o arcabouço legal do endividamento público em um estado federalizado exige o enfrentamento de dois temas jurídicos que isoladamente já se mostram complexos: o federalismo brasileiro e a autonomia financeira dos seus entes subnacionais.

A República Federativa do Brasil conjuga características de um federalismo dualista com elementos cooperativos ${ }^{11}$, quer dizer, mescla competências exclusivas de cada um dos seus entes com competências a serem exercidas concorrentemente.

Nesse contexto, o endividamento público dos entes subnacionais é objeto da política financeira, interferindo, por conseguinte, na política macroeconômica do governo central, sendo a sua gestão competência da União, conforme análise sistêmica de diversos dispositivos constitucionais (arts. 21, VII e VIII, 22, VI, VII e VIII e 24, I, todos da CF/88).

Segundo Rigolon e Giambiagi ${ }^{12}$, a ideia do federalismo fiscal ganhou força nas décadas de 1980 e 1990, em prol de uma maior eficiência alocativa, uma vez

10 Sobre a natureza jurídica da dívida pública, seus elementos, conceitos e classificações ver: LOCHAGIN, Gabriel Loretto. Dívida pública: conceito, tipos e natureza jurídica, cit., p. 2768; e ANDRADE, Cesar Augusto Seijas de. O controle do endividamento público e a autonomia dos entes da federação, cit., 2012.

11 Cf. FARIA, Rodrigo Oliveira de. Reflexos do endividamento nas relações federativas brasileiras. In: CONTI, José Mauricio; SCAFF, Fernando Facury; BRAGA, Carlos Eduardo Faraco (org.). Federalismo fiscal: questões contemporâneas. Florianópolis: Conceito Editorial, 2010, p. 442.

12 Cf. RIGOLON, Francisco José Zagari; GIAMBIAGI, Fabio. A renegociação das dívidas e regime fiscal dos estados. In: GIAMBIAGI, Fabio; MOREIRA, Maurício Mesquita (org.). A economia brasileira nos anos 90. Rio de Janeiro: Banco Nacional de Desenvolvimento Econômico e Social, 1999. p. 34. 
que a repartição dos recursos disponíveis permite que os diversos entes federativos ofereçam uma cesta de bens e serviços públicos maior e melhor aos seus cidadãos, o que não ocorreria de maneira tão eficiente se o provimento desses bens ocorresse a partir do governo central, que está distante dos beneficiários.

Como bem salientado por Rodrigo de Oliveira Faria ${ }^{13}$ :

Muito embora a política macroeconômica seja de competência da União, o comportamento e as diretrizes adotadas pelos governos subnacionais interferem no alcance dos objetivos estabelecidos pelo governo central e, portanto, na condução daquela política, em virtude do gasto agregado de que se fazem portadores, bem com o de seus níveis de endividamento.

Nesse sentido, apesar dos riscos envolvidos, é estruturalmente relevante para o país preservar a autonomia financeira dos entes federados e, por conseguinte, garantir-lhes o acesso aos mercados financeiros, pois, dessa forma, o governo central contribui para a expansão do investimento em infraestrutura e para o cumprimento das competências constitucionais materiais.

Entretanto, do próprio conceito de autonomia ${ }^{14}$ e seus elementos ${ }^{15}$ reconhece-se a existência de restrições - maiores ou menores - impostas pela Constituição Federal e pelas Constituições Estaduais aos entes subnacionais. Observa-se que a própria atribuição de competência dada a um ente da Federação opera como restrição à atuação das demais entidades componentes do Estado.

${ }^{13}$ Cf. FARIA, Rodrigo Oliveira de. Reflexos do endividamento nas relações federativas brasileiras, cit., p. 445.

14 Segundo José Afonso da Silva (apud CONTI, 2003, p. 1079) “Autonomia envolve capacidade normativa sobre assuntos de competência exclusiva da entidade autônoma. Para que uma entidade possa ser considerada autônoma é necessário, no mínimo, a existência de governo próprio e existência de competência exclusiva, conforme ensina Charlles Durand, que acrescente que governo próprio significa governo formado sem interferência de outra entidade, isto é, governo proveniente de escolha da própria comunidade autônoma. Competência exclusiva constitui-se de uma área de poder próprio, outorgado à entidade autônoma para desenvolvimento de sua capacidade normativa".

15 Dois são os elementos essenciais e irredutíveis do conceito de autonomia; (a) existência de órgãos governamentais próprios; e (b) posse de competências exclusivas. Tais elementos compõem o significado do termo autonomia nas palavras de José Afonso da Silva: "governo próprio dentro do círculo de competências traçadas pela Constituição FederaI" (FARIA, Rodrigo de Oliveira. Reflexões do endividamento nas relações federativas brasileiras. In: CONTI, José Mauricio; SCAFF, Fernando Facury; BRAGA, Carlos Eduardo Faraco (org.). Federalismo fiscal: questões contemporâneas. Florianópolis: Conceito Editorial, 2010, p. 439. 
A autonomia pode ser categorizada a partir de três aspectos: político, administrativo e financeiro ${ }^{16}$. A autonomia financeira, que aqui nos interessa, exterioriza-se por meio de diversas atribuições constitucionais de competências aos Estados e aos Municípios, sendo a possibilidade de um ente público subnacional contrair dívida uma das formas pela qual ela se expressa.

Sobre o exercício da autonomia financeira na perspectiva do crédito e da dívida pública, leciona José Mauricio Conti ${ }^{17}$ que:

O pleno exercício deste aspecto da autonomia, por parte da entidade subnacional, sem qualquer limitação, tem demonstrado ao longo do tempo que pode ser prejudicial à população que integra referido ente da Federação, dada a forma irresponsável com que as finanças públicas são às vezes administradas.

Por conseguinte, a questão que se coloca à frente para debate é sobre a não efetividade normativa histórica dos limites legalmente impostos pelo governo central para o exercício dessa feição da autonomia dos entes subnacionais, diante da inoperância do controle externo ante um endividamento público crescente e o surgimento de crises financeiras redundantes e renegociações fiscais sucessivamente fracassadas.

\subsection{Os programas de reestruturação fiscal e financeira no panorama pós-Constituição Federal de 1988}

Em 1930, no auge do enfrentamento de uma crise financeira mundial, Getúlio Vargas, ao assumir o Governo Provisório, apresentou um programa de reconstrução nacional ${ }^{18}$, sob o comando de Valentim Bouças ${ }^{19}$, que contemplava a

${ }_{16}$ Cf. CONTI, José Mauricio. Dívida pública e responsabilidade fiscal no federalismo brasileiro, cit., p. 1080-1084.

17 Cf. CONTI, José Mauricio. Divida pública e responsabilidade fiscal no federalismo brasileiro, cit., p. 1092.

18 Decreto n. 20.631 de 9 de novembro de 1931 que "institui uma comissão de técnicos para proceder a estudos financeiros e econômicos dos Estados e Municípios”. Disponível em: http:// www2.camara.leg.br/legin/fed/decret/1930-1939/decreto-20631-9-novembro-1931-509261-publicacaooriginal-1-pe.html.

19 Valentim Bouças era o representante Técnico dos Ministérios da Fazenda e Justiça, foi nomeado Secretário Geral da comissão que tinha como principal objetivo organizar a situação econômico-financeira do país, de modo a consolidar todas as informações econômicas relevantes de todos os entes estatais e divulga-las através de uma série chamada de Finanças do Brasil que consta de 21 volumes entre 1932 e 1957 (Disponível em: www.memoria.org.br). 
reorganização e unificação das finanças dos Estados e dos Municípios e a regularização dos seus empréstimos externos.

Observa-se a partir de relevante fato histórico das finanças públicas brasileiras que, há quase um século, já havia o consenso de que, para a organização econômico-financeira de todo o país, é fundamental ter o controle dos quadros econômicos e financeiros dos seus entes federados, principalmente no que concerne às suas dívidas internas e externas.

Apesar desse entendimento, na história recente do endividamento público brasileiro, ocorreram consecutivos programas de recuperação fiscal voltados aos entes subnacionais, por meio de edições de medidas provisórias e/ou de leis, antes e depois da vigência da LRF e das edições das RSF n. 40 e 43, de 2001.

Desde já, não é demasiado afirmar que na federação brasileira prevalece a prática da socialização das perdas ou da socialização da gestão fiscal irresponsável, mesmo com a existência secular de diversas Cortes de Contas incumbidas da fiscalização das receitas e dos gastos dos entes federados. Sobre essa lesiva prática, salienta Faria ${ }^{20}$ :

$\mathrm{Na}$ medida em que entidades subnacionais contem com o seguro amparo e o beneplácito do governo federal aos seus desequilíbrios financeiros, nenhum incentivo haveria em se proceder de forma responsável no âmbito fiscal. Mais do que isso, a gestão fiscal irresponsável de uma determinada entidade federativa implicaria em um ônus a ser partilhado entre todos os entes da Federação, em visível afronta ao princípio da isonomia.

Com a promulgação da $\mathrm{CF} / 88$, houve um rearranjo do federalismo fiscal no Brasil. O governo central perdeu parcela considerável de suas receitas para os estados e os municípios, sem que tal movimento fosse acompanhado da transferência da responsabilidade pelos dispêndios financeiros na mesma proporção.

Também sobre essa cultura da irresponsabilidade generalizada dos governos subnacionais, contextualizaram Rigolon e Giambiagi ${ }^{21}$ :

No entanto, a experiência recente de muitos países em desenvolvimento sugere que, nas circunstâncias atuais, os governos subnacionais contribuem -

20 Cf. FARIA, Rodrigo Oliveira de. Reflexões do endividamento nas relações federativas brasileiras, cit., p. 446.

21 Cf. RIGOLON, Francisco José Zagari; GIAMBIAGI, Fabio. A renegociação das dívidas e regime fiscal dos estados. In: GIAMBIAGI, Fabio; MOREIRA, Maurício Mesquita (org.). A economia brasileira nos anos 90. Rio de Janeiro: Banco Nacional de Desenvolvimento Econômico e Social, 1999, p. 122. 
muitas vezes, significativamente - para agravar os problemas macroeconômicos ou dificultar a sua solução.

Primeiro porque os governos subnacionais são incentivados a produzir déficits e a transferir o seu financiamento para o governo central. Quando os recursos não estão disponíveis ex-ante no governo nacional, eles podem ficar disponíveis ex-post, depois da realização do gasto e da acumulação da dívida. O poder político de muitos governos subnacionais e as implicações sistêmicas e políticas da eventual deterioração de suas contas diminuem a capacidade de o governo central resistir às pressões por mais recursos.

Segundo porque a crença na capacidade de o governo central assegurar, em última instância, a solvência dos governos subnacionais cria um problema de perigo moral que estimula o endividamento excessivo. Em geral, uma multiplicidade de agentes estará disposta a financiar os governos subnacionais, com base numa garantia explícita ou implícita do governo federal.

Após a promulgação $\mathrm{CF} / 88$, a primeira medida de reestruturação da dívida subnacional mais consistente se deu com a promulgação da Lei n. 7.976/89, que permitiu ao governo central assumir o endividamento externo desses entes, com prazo de pagamento de 20 anos.

Em 1991, o governo federal possibilitou o refinanciamento da dívida dos estados com o Fundo de Garantia por Tempo de Serviço (FGTS), com a edição da Lei n. 8.212/91. Posteriormente, em 1993, foi dada a oportunidade de refinanciamento da dívida dos Estados com o Instituto Nacional do Seguro Social (INSS), autorizado pela Lei n. 8.620/93.

Advinda de uma demanda crescente por um reescalonamento, mais uma rodada de renegociação, em 1993, resultou na edição da Lei n. 8.727/93. Sobre essa normatização asseveram Fábio Giambiagi e Mônica Mora ${ }^{22}$ que:

Essa lei, contudo, se limitou à dívida de estados e municípios com a União e instituições federais, frustrando as expectativas dos governadores e prefeitos. Parte significativa da dívida subnacional permanecia em poder da iniciativa privada, sendo essa parcela a principal responsável pela trajetória explosiva do endividamento observada após 1994.

O Conselho Monetário Nacional (CMN), por meio da Resolução n. 2.008/93, proibiu o aumento da participação dos bancos privados na dívida esta-

22 Cf. MORA, Mônica; GIAMBIAGI, Fábio. Federalismo e endividamento subnacional: uma discussão sobre a sustentabilidade da dívida estadual e municipal. Disponível em: http://www. ipea.gov.br. 
dual. Com a promulgação da Emenda Constitucional n. 3, de 17 de março de 1993, restringiu-se a emissão de títulos de dívida pelos Estados, Municípios e Distrito Federal até 31 de dezembro de 1999.

Em seguida, o Senado Federal editou a Resolução n. 11/94, que "dispõe sobre as operações de crédito interno e externo dos Estados, do Distrito Federal, dos Municípios e de suas autarquias, inclusive concessão de garantias, seus limites e condições de autorização", exercendo, dessa forma, sua competência privativa estabelecida no art. 52, incisos VI, VII, VIII e IX da Constituição da República de 1988.

Em 1995, o Conselho Monetário Nacional aprovou o Programa de Saneamento Financeiro e de Ajuste Fiscal dos Estados, que previa refinanciamento de operações de Antecipação de Receita Orçamentária (ARO) e criava linhas de crédito para pagamento de pessoal e outras obrigações de curto prazo. Em contrapartida, os estados deveriam adotar medidas de austeridade fiscal e privatizar estatais.

No exercício seguinte, foi editada a Medida Provisória n. 1.514/96, que estabelecia "mecanismos objetivando incentivar a redução da presença do setor público estadual na atividade financeira bancária, dispondo sobre a privatização de instituições financeiras".

Finalmente, em 1997, foi editada a Medida Provisória n. 1.560, posteriormente convertida na Lei n. 9.496, de 11 de setembro de 1997 (Programa de Reestruturação e de Ajuste Fiscal - PAF), disciplinando os "critérios para a consolidação, a assunção e o refinanciamento, pela União, da dívida pública mobiliária e outras que especifica, de responsabilidade dos Estados e do Distrito Federal".

Entretanto, as condições estabelecidas nos contratos firmados se tornaram insustentáveis com o passar do tempo, especialmente em relação ao indexador e aos juros reais definidos (forte elevação do IGP-DI, decorrente da depreciação da taxa de câmbio, levou a um subsídio negativo, já que o custo dos contratos foi superior à taxa de mercado).

Com a promulgação da Lei Complementar n. 148/14, que estabeleceu normas de finanças públicas voltadas para a responsabilidade na gestão fiscal, lançou-se uma proposta no sentido de aliviar as finanças públicas das entidades pactuantes e ajustar os termos do contrato aos novos parâmetros macroeconômicos.

Resta evidente que a cultura da irresponsabilidade fiscal, com a federalização das perdas, sempre permeou a gestão financeira dos governos locais, como bem anota Francisco Luiz Cazeiro Lopreato ${ }^{23}$ :

23 Cf. LOPREATO, Francisco Luiz Cazeiro. O colapso das finanças estaduais e a crise da federação. São Paulo: Unesp, 2002, p. 147-148. 
A resistência dos governadores em aceitarem cortes nos gastos públicos criou obstáculos à definição de uma política de reciclagem das dívidas e de contratação de créditos suplementares, contrárias a seus interesses. Essa posição descortinava um vasto campo de atrito entre os governadores e os formuladores de política econômica, pois a posição dos Estados entrava em choque com os objetivos macroeconômicos.

Os governadores perderam parcela apreciável de tempo e de energia política na tentativa de contornar os problemas do endividamento e viabilizar um cronograma de gastos compatível com a expectativa dos Estados. As negociações em torno da dívida e das oportunidades de novas operações de crédito assumiram papel decisivo na atuação dos Estados, no jogo de interesses e nas manobras políticas, definindo os parâmetros das relações entre a União e os governos estaduais. Além disso, abriram brechas aos acordos políticos que tinham como objetivo acomodar as diretrizes da área econômica, as preocupações das autoridades estaduais e a vontade do Congresso.

Recentemente, foram editadas as Leis Complementares n. 156/2016 e 159/2017, a primeira estabeleceu o plano de auxílio aos Estados e ao Distrito Federal e medidas de estímulo ao reequilíbrio fiscal, e a segunda instituiu o Regime de Recuperação Fiscal dos Estados e do Distrito Federal.

No exercício de 2017, o PAF foi aprimorado com a implementação das mudanças previstas na Lei Complementar n. 156/16, que alterou as seis metas fiscais dos Programas e estabeleceu que os conceitos e definições neles utilizados deverão ser os mesmos da LRF. As mudanças estão regulamentadas pela Portaria STN n. 690/17.

O resultado desses programas e a situação das dívidas dos Estados e dos Municípios podem ser analisados no Boletim de Finanças dos Entes Subnacionais da Secretaria do Tesouro Nacional ${ }^{24}$, do qual também se extrai o Resultado Orçamentário por ente da federação.

Assim, ao analisar a linha do tempo acima relatada, é perceptível a falência do controle da dívida pública, tendo em vista que, mesmo com os sucessivos programas de recuperação fiscal, o rigor da LRF e a estipulação de limites para a contratação de operações de crédito, os Estados e os Municípios do Brasil encontram-se ainda em situação de desequilíbrio fiscal, o qual decorre, dentre outras causas, da não operacionalização do controle externo, legalmente instituído, sobre a gestão do endividamento público.

24 BRASIL. Secretaria do Tesouro Nacional. Boletim de Finanças dos Entes Subnacionais. Disponível em: http://www.tesouro.fazenda.gov.br/-/stn-divulga-novo-boletim-de-financas-de-estados-e-municipios. 


\subsection{As normas que versam sobre os limites do endividamento público versam sobre o seu controle externo}

Segundo Teresa Ter-Minassian e John Craig ${ }^{25}$, existem basicamente três métodos que os Estados modernos utilizam para a fixação de limites às operações de crédito, especialmente quando se referem ao endividamento das entidades federadas, quais sejam: cooperative approach, ruled-based approaches e direct control of the Central Government.

Sem adentrar na discussão sobre qual dos métodos elencados pela autora é o mais eficiente, o fato é que o Brasil fixa os limites das dívidas públicas dos entes subnacionais e o seu controle por meio de normas jurídicas e controle administrativo ${ }^{26}$.

Verifica-se que parte das regras que disciplinam o endividamento público está positivada na própria Constituição, regulamentada pelas legislações infraconstitucionais: LRF e as RSF n. 40 e 43, de 2001.

Como já citado anteriormente, os Estados, os Municípios e o Distrito Federal submetem-se à política de crédito fixada pela União, em razão da disposição constitucional constante no art. 22, VII, o qual atribui ao ente central a competência privativa para legislar sobre política de crédito, câmbio, seguros e transferência de valores.

Conforme aponta Cesar Augusto Seijas de Andrade ${ }^{27}$ :

A competência legislativa da União sobre a matéria é exercida por normas editadas pelo Congresso Nacional e pelo Senado Federal. De acordo com o art. 48, II da Constituição, cabe ao Congresso Nacional, com a sanção do Presidente da República, dispor sobre operações de crédito e dívida pública. Ao Congresso Nacional também compete, conforme determina o art. 48, XIV da Constituição, dispor sobre o montante da dívida mobiliária federal.

Cumprindo a determinação do sistema financeiro constitucional, foi editada a LRF, que estabelece normas de finanças públicas voltadas para a responsabilidade na gestão fiscal (art. $1^{\circ}$ ), buscando, com isso, obter "uma drástica e veloz

${ }^{25}$ Cf. TER-MINASSIAN, Teresa; CRAIG, Jon. Control of subnational government borrowing. In: TER-MINASSIAN, Teresa (ed.). Fiscal federalism in theory and practice. Washington: International Monetary Fund, 1997, p. 164-169.

26 Cf. ANDRADE, Cesar Augusto Seijas de. O controle do endividamento público e a autonomia dos entes da federação, cit., p. 65.

27 Cf. ANDRADE, Cesar Augusto Seijas de. O controle do endividamento público e a autonomia dos entes da federação, cit., p. 65. 
redução do déficit público e a estabilização do montante da dívida pública em relação ao Produto Interno Bruto da Economia ${ }^{28}$ ".

As diretrizes para uma gestão fiscal responsável vêm estabelecidas no art. $1^{\circ}$, $\mathbb{S} 1^{\circ}$ da LRF, ao dispor que "a responsabilidade na gestão fiscal pressupõe a ação planejada e transparente, em que se previnem riscos e corrigem desvios capazes de afetar o equilíbrio das contas públicas, mediante o cumprimento de metas de resultados entre receitas e despesas e a obediência a limites e condições no que tange a renúncia de receita, geração de despesas com pessoal, da seguridade social e outras, dívidas consolidada e mobiliária, operações de crédito, inclusive por antecipação de receita, concessão de garantia e inscrição em Restos a Pagar”.

Constata-se, assim, que uma das principais finalidades da Lei de Responsabilidade Fiscal é a limitação do endividamento público, como forma de evitar, além do excesso de dívida, danos presentes e futuros para a gestão fiscal.

Nos termos do art. 52 da Constituição Federal, os limites serão fixados pelo Senado Federal por meio de resolução. Em obediência ao comando constitucional, foram editadas as RSF n. 40 e 43, de 2001, que são os principais diplomas atualmente vigentes que veiculam as normas limitadoras do endividamento público dos Estados e Municípios.

Dada a dimensão do trabalho proposto e em razão de o objetivo central ser o controle externo sobre o cumprimento dos limites da dívida pública, importa nesse momento firmar a seguinte constatação: nos mesmos diplomas legais que disciplinam as regras e os limites para o endividamento dos entes subnacionais (CF/88, LRF e RSF n. 40 e 43, de 2001) encontram-se inseridas também as obrigações para o exercício da fiscalização pelos Tribunais de Contas em relação a esse objeto.

Como se verá em seguida, tanto os constitucionalistas, originários e derivados, quanto os legisladores infraconstitucionais preocuparam-se com a instituição e a definição do campo de atuação do controle externo em relação ao endividamento público dos entes federados.

\section{OS TRIBUNAIS DE CONTAS DOS ENTES DA FEDERAÇÃO E O EFETIVO EXERCÍCIO DO CONTROLE EXTERNO DO ENDIVIDAMENTO PÚBLICO}

Sobre a relevância da atuação dos Tribunais de Contas para a saúde das finanças públicas, destaca-se o ensinamento de José Mauricio Conti ${ }^{29}$ :

28 Cf. CONTI, José Mauricio. Artigos 32 a 39. In: MARTINS, Ives G. S.; NASCIMENTO, Carlos V. (coord.). Comentários à lei de responsabilidade fiscal. 6. ed. São Paulo: Saraiva, 2012, p. 275-305.

${ }^{29}$ Cf. CONTI, José Mauricio. Tribunais de Contas são os guardiões do dinheiro público. In: CONTI, José Mauricio. Levando o direito financeiro a sério. São Paulo: Blucher, 2016, p. 184. 
Os Tribunais de Contas dispõem de instrumentos eficientes para evitar o mau uso do dinheiro público, como os alertas a que se refere o artigo 59, parágrafo $1^{\circ}, \mathrm{V}$, da Lei de Responsabilidade Fiscal, com os quais informam os gestores sobre ultrapassagem de limites de gastos e endividamento, indícios de irregularidades e outros que possam comprometer a boa gestão das contas públicas. Atualmente tem sido intensificado seu uso, mostrando esta importante ação de natureza preventiva, seguramente a melhor forma de evitar a má gestão das contas públicas.

Tratando especificamente do controle da dívida pública, a atuação dos Tribunais de Contas está contemplada na redação do art. 71, inciso I, da Constituição Federal, que remete à apreciação das contas prestadas anualmente pelos chefes do Poder Executivo, além de lhes atribuir a competência para realizar trabalhos de fiscalização específicos.

As Cortes de Contas atuam também sob o amparo do art. $59, \mathbb{\$} 1^{\circ}$, inciso III da Lei de Responsabilidade Fiscal, que dispõe que os Tribunais de Contas alertarão o respectivo Poder Executivo quando constatarem que os montantes das dívidas consolidadas e mobiliárias, das operações de crédito e da concessão de garantias se encontrarem acima de $90 \%$ dos respectivos limites.

Será ressaltado, nesta seção do artigo, o potencial subutilizado das auditorias de controle externo sobre o endividamento público a serem realizadas pelo corpo técnico das Cortes de Contas.

\subsection{As competências constitucionais e legais dos Tribunais de Contas dos entes subnacionais}

No Brasil, a fiscalização financeira, orçamentária, contábil, operacional e patrimonial da Administração Pública é exercida pelo Parlamento, com o auxílio do Tribunal de Contas. É o que dispõe o art. 71, caput, da CF/88, verbis: "O controle externo, a cargo do Congresso Nacional, será exercido com o auxílio do Tribunal de Contas da União, ao qual compete (...)". De acordo com o art. 75, caput, da CF/88, esse modelo deve ser estendido às demais esferas da federação, e, portanto, para as suas respectivas Cortes de Contas.

Em linhas gerais, a organização, a composição e as competências dos Tribunais de Contas do Brasil estão definidas na CF/88, nos arts. 70 a 75 , o que garante certa uniformidade entre os entes federados. Portanto, por expressa disposição constitucional, as normas que disciplinam o TCU aplicam-se simetricamente às Cortes de Contas dos entes subnacionais.

Já os detalhes do trâmite processual, nos procedimentos dos Tribunais de Contas, costumam ser regulados por suas Leis Orgânicas, que são editadas pelo Poder Legislativo, ao qual a Corte de Contas está integrada. 
Além das competências previstas na CF/88, há diversos diplomas legais que contemplam os Tribunais de Contas no sistema de controle do endividamento público, tais como a Lei de Responsabilidade Fiscal (Lei Complementar n. 101/2000), as RSF n. 40 e 43, de 2001, a Lei Geral de Licitações e Contratos (Lei n. 8.666/93), a Lei dos Crimes Fiscais (Lei Federal n. 10.028/2000) e as Leis Orgânicas dos Tribunais de Contas.

A já clássica divisão doutrinária proposta pelo Ministro do TCU, Exmo. Sr. Valmir Campelo, no Encontro Luso-Brasileiro de Tribunais de Contas realizado em Portugal, no ano de $2003^{30}$, agrupa as competências dos órgãos de controle externo em fiscalizadora, judicante, sancionadora, consultiva, informativa, corretiva, normativa e ouvidoria.

Para o estudo do exercício do controle externo do endividamento dos entes subnacionais, interessam sobretudo as funções consultiva, fiscalizadora e sancionadora, que se sustentam, sobretudo, na atuação do corpo técnico multidisciplinar desses órgãos, por meio de auditorias e inspeções, as quais estão em constante aperfeiçoamento.

\subsection{As normas que balizam o exercício do controle externo do endividamento público}

No tocante ao endividamento público, as Cortes de Contas atuam sob o amparo dos arts. $57 \mathrm{c} / \mathrm{c} 59$, inciso II e $\mathbb{S} 1^{\circ}$, inciso III da Lei de Responsabilidade Fiscal, que dispõem, respectivamente, que os Tribunais de Contas emitirão parecer prévio conclusivo sobre as contas prestadas pelos Chefes do Poder Executivo, fiscalizarão os limites e condições para realização de operações de crédito e alertarão o respectivo Poder Executivo quando constatarem que os montantes das dívidas consolidada e mobiliária, das operações de crédito e da concessão de garantias se encontrarem acima de $90 \%$ dos respectivos limites.

Em cumprimento aos incisos VI e IX do art. 52 da CF/88 e ao art. 30, inciso I da LRF, o Senado Federal aprovou as Resoluções n. 40, de 20 de dezembro de 2001, e 43, de 21 de dezembro de 2001, que estabelecem limites globais de endividamento e sobre operações de crédito para os Estados, Distrito Federal e Municípios.

A Resolução n. 43/2001 disciplina as operações de crédito interno e externo dos Estados, do Distrito Federal e dos Municípios, inclusive concessão de garantias, seus limites e condições de autorização. Nela, há diversos dispositivos que

${ }^{30}$ Encontro Luso-Brasileiro de Tribunais de Contas realizado em Portugal, no ano de 2003. Disponível em: https://www.tcontas.pt/pt/publicacoes/outras/enc_luso-brasileiro/enc_luso-brasileiro.pdf, p. 47. 
inserem os Tribunais de Contas na sistemática normativa dos pleitos para a realização de operações de crédito, elevando, assim, a necessária participação desses órgãos na fiscalização e na gestão da dívida pública dos Estados, dos Municípios e do Distrito Federal.

Infere-se que a CF/88 e a legislação infraconstitucional trazem um rol de regras direcionadas às Cortes de Contas, que revelam a indispensável atuação desses órgãos no exercício do controle externo do endividamento público dos entes federados.

Em resumo, em conformidade com a RSF n. 43/2001, a fiscalização dos Tribunais de Contas nos pleitos para a realização de operação de crédito se dá com o seguinte procedimento:

a) Expedição de certidão que comprove a regularidade da emissão dos títulos públicos para o pagamento de precatórios judiciais (art. 13, $\mathbb{S} 1^{\circ}$ );

b) A comprovação do disposto no inciso II do art. 18 será feita por meio de certidão do Tribunal de Contas a que esteja jurisdicionado o garantidor ou, alternativamente, mediante declaração fornecida pelo Estado, Distrito Federal ou Município que estiver concedendo a garantia, diretamente ou por meio do agente financeiro que estiver operacionalizando a concessão da garantia $\left(\operatorname{art.} 18, \mathbb{S} 2^{\circ}\right.$ );

c) Os Estados, o Distrito Federal e os Municípios encaminharão ao Ministério da Fazenda os pedidos de verificação de limites e condições para a realização das operações de crédito de que trata essa Resolução, com a proposta do financiamento ou empréstimo e instruídos com: IV - certidão expedida pelo Tribunal de Contas competente atestando: a) em relação às contas do último exercício analisado, o cumprimento do disposto no $\mathbb{S} 2^{\circ}$ do art. 12 ; no art. 23 ; no art. 33 ; no art. 37; no art. 52; no $\mathbb{S} 2^{\circ}$ do art. 55 ; e no art. 70 , todos da Lei Complementar n. 101, de 2000; b) em relação às contas dos exercícios ainda não analisados, e, quando pertinente, do exercício em curso, o cumprimento das exigências estabelecidas no $\mathbb{2} 2^{\circ}$ do art. 12 ; no art. 23 ; no art. 52 ; no $\mathbb{} 2^{\circ}$ do art. 55; e no art. 70, todos da Lei Complementar n. 101, de 2000, de acordo com as informações constantes nos relatórios resumidos da execução orçamentária e nos de gestão fiscal; c) a certidão deverá ser acompanhada de declaração do chefe do Poder Executivo de que as contas ainda não analisadas estão em conformidade com o disposto na alínea $a$; (art. 21, inciso IV, alíneas $a, b$ e $c$ );

d) A devolução de que trata o art. 24 deverá ser comunicada ao Poder Legislativo local e ao Tribunal de Contas a que estiver jurisdicionado o pleiteante (art. 24); 
e) A conclusão do processo de regularização de que trata os $\mathbb{S} \mathbb{S} 4^{\circ}$ e $6^{\circ}$ do art. 24 será encaminhada pelo Ministério da Fazenda ao Poder Legislativo local e ao Tribunal de Contas a que estiver jurisdicionado o pleiteante $\left(\operatorname{art.} 24, \mathbb{S} 7^{\circ}\right)$;

f) $\mathrm{O}$ resultado do processo competitivo de que trata o $\mathbb{S} 1^{\circ}$ do art. 37 será divulgado pelo Banco Central do Brasil, sempre que possível por meio eletrônico, a todas as instituições financeiras, ao Senado Federal, ao Ministério da Fazenda, ao Poder Legislativo do Estado, do Distrito Federal ou do Município, conforme o caso, e ao Tribunal de Contas competente, com descrição detalhada das ofertas realizadas (art. 37, $\mathbb{S} 2^{\circ}$ );

g) Após a realização do leilão eletrônico, o Banco Central do Brasil encaminhará as informações relevantes sobre ele, sempre que possível por meio eletrônico, às instituições financeiras, ao Ministério da Fazenda, ao Senado Federal, ao Poder Legislativo do Estado, do Distrito Federal ou do Município, conforme o caso, e ao Tribunal de Contas competente (art. 39);

h) A fiscalização quanto à correta utilização dos recursos arrecadados com a venda dos títulos vinculados ao disposto no art. 33 do Ato das Disposições Constitucionais Transitórias compete aos Tribunais de Contas a que estão jurisdicionadas as entidades emissoras (art. 45). A Comissão de Assuntos Econômicos do Senado Federal poderá, havendo evidências de irregularidade, realizar diligência nos termos do $\mathbb{S} 3^{\circ}$ do art. 24 ou solicitar ao respectivo Tribunal de Contas que realize auditoria na aplicação dos recursos obtidos por meio da colocação dos títulos de que trata o caput (parágrafo único) (grifos nossos).

Destaca-se o disposto na alínea $h$, que confere ampla liberdade de atuação dos Tribunais de Contas na instauração de fiscalizações específicas (auditorias) para examinar de forma aprofundada a aplicação dos recursos obtidos por meio do endividamento.

Apesar das balizas normativas vigentes, como muito bem anota José Mauricio Conti ${ }^{31}$, a questão dos limites da dívida pública permanece bastante tormentosa, não tendo sido fixados critérios absolutamente precisos e objetivos na doutrina que possam servir como parâmetro para a criação de regras limitadoras do endividamento, o que demanda ainda mais atenção dos órgãos de fiscalização,

31 Cf. CONTI, José Mauricio. Artigos 32 a 39. In: MARTINS, Ives G. S.; NASCIMENTO, Carlos V. (coord.). Comentários à lei de responsabilidade fiscal, cit., p. 11. 
notadamente dos Tribunais de Contas no exercício do controle externo prévio, concomitante e efetivo do endividamento público dos entes subnacionais.

Assim, dadas a versatilidade e a capacidade evolutiva das auditorias e inspeções como condutoras da atuação dos Tribunais de Contas e principalmente em razão do aperfeiçoamento do conhecimento multidisciplinar dos auditores de controle externo, passou o tempo em que os Tribunais de Contas se ocupavam apenas da fiscalização de conformidade, sob o aspecto da legalidade, concentrando-se somente nas formalidades da realização despesa pública.

Sobre esse aspecto da atuação dos Tribunais de Contas, de forma precisa, ressaltaram Moutinho e Lochagin ${ }^{32}$ :

Deve-se destacar que o acompanhamento da gestão fiscal pelos tribunais de contas não se restringe à conferência dos cálculos apresentados nos demonstrativos e verificação se eles são superiores aos limites estabelecidos. No exercício dessa atividade, as cortes de contas, também, analisam a conformidade da metodologia empregada pela administração na elaboração de seus relatórios e demonstrativos e examinam o conteúdo contabilizado em cada rubrica, verificando sua adequação à metodologia adotada. Como exemplos de atuação do TCU nesse sentido podemos citar os Acórdãos n. 1.051/2007-Plenário, n. 1.779/2009-Plenário, n. 435/2009-Primeira Câmara e 5403/2009-Primeira Câmara.

Contribui ainda para o fortalecimento e aprofundamento dos trabalhos das Cortes de Contas Nacionais e Subnacionais a utilização de padrões de auditoria reconhecidos internacionalmente ${ }^{33}$. Tais normas técnicas de auditoria constituem-se em um relevante instrumento de melhoria do controle e da gestão pública brasileira.

São cada vez mais frequentes relatórios sobre contas de governos mais abrangentes, com avaliação macro das finanças governamentais e das políticas públicas que vêm sendo desenvolvidas, apontando falhas e sugerindo soluções e aperfeiçoamentos, tornando os Tribunais de Contas órgãos que atuam de forma preventiva e concomitante, e não apenas na fiscalização a posteriori.

É possível afirmar que o avanço institucional das Cortes de Contas Subnacionais na fiscalização da qualidade do gasto público, levando-se em considera-

32 Cf. LOCHAGIN, Gabriel Loretto; MOUTINHO, Donato Volkers. Controle da gestão da dívida pública federal. Revista do Mestrado em Direito da Universidade Católica de Brasília (RVMD), Brasília, v. 11, n. 2, jul./dez. 2017, p. 66.

33 Normas Internacionais de Auditoria das Entidades Fiscalizadoras Superiores (ISSAI), emitidas pela Organização Internacional de Entidades Fiscalizadoras Superiores (INTOSAI), que no Brasil convergem para Normas Brasileiras de Auditoria do Setor Público (NBASP). 
ção a eficácia, a efetividade, a eficiência e a economicidade no uso dos recursos públicos, ainda não repercutiu positivamente na fiscalização do endividamento público e da gestão dos riscos fiscais decorrentes da sua insustentabilidade.

Corrobora com essa visão a última publicação do Boletim de Finanças dos Entes Subnacionais 201734, da Secretaria do Tesouro Nacional (STN), onde se constata, por exemplo, que os Estados do Rio de Janeiro, do Rio Grande do Sul e de Minas Gerais ultrapassaram o limite do endividamento imposto pelo art. $3^{\circ}$, inciso I da RSF n. 40/2001.

$\mathrm{O}$ aprofundamento da crise fiscal nessas esferas políticas chegou a um nível em que há escassez de recursos para arcar com o funcionalismo público e honrar fornecedores, prejudicando a prestação de inúmeros serviços públicos essenciais.

De fato, diversos entes federativos estão à beira da insolvência e já descumprindo reiteradamente os limites impostos pela LRF. Isso significa que, além dos riscos fiscais envolvidos, há riscos sociais e político-institucionais. Questiona-se: quais as providências (fiscalizações específicas) que estão sendo tomadas no âmbito das Cortes de Contas dos Estados e dos Municípios no sentido de verificar as causas das atuais crises fiscais dos seus respectivos entes e quais as medidas a serem tomadas para prevenir crises futuras?

As recentes aprovações de auditorias pelo TCU, cujo objeto é a dívida pública interna federal e os vários elementos financeiros e orçamentários que a compõem, apontam um caminho a ser seguido. A Corte de Contas Federal vem atuando por meio de processos de auditorias conexos e complementares para a elucidação de diversas questões relacionadas à dívida pública interna federal, como se observa na compilação de processos abaixo extraída de acórdãos ${ }^{35}$ julgados:

a) Auditoria de Conformidade, autuada sob o TC 021.465/2010-0, realizada no Banco Central do Brasil (Bacen) e na Secretaria do Tesouro Nacional (STN), decorrente do Acórdão 1.293/2010-TCU-Plenário (TC 013.395/2010-6);

34 BRASIL. Ministério da Fazenda. Secretaria do Tesouro Nacional (STN). Boletim de Finanças dos Entes Subnacionais 2017: Brasília: STN, 2017. Disponível em: http://tesouro.gov.br/documents/10180/617267/Boletim+entes+6dez17/cffd7d36-5497-42e7-ab45-9ca0d4762d19. Acesso em: 18 jul. 2018. p. 35.

35 BRASIL. Tribunal de Contas da União. Acórdão 1.776/2012, Processo n. TC 021.465/2010-0, Relator Walton Alencar Rodrigues, Plenário. Ata n. 26/2012. Data da sessão: 11/07/2012 Ordinária.

BRASIL. Acórdão 571/2017, Processo n. TC 033.619/2016, Relator Ministro Aroldo Cedraz, Plenário, Ata n. 10/2017. Data da Sessão: 29/03/2017 - Ordinária. 
b) Auditoria aprovada na sessão plenária, desta Corte de Contas, de 1\%/2/2017 e autuada sob o TC 003.365/2017-4, sobre os critérios e condicionantes verificados por ocasião da concessão de garantias, notadamente no que diz respeito ao procedimento de análise de capacidade de pagamento dos beneficiários, as causas, os montantes e os possíveis riscos decorrentes de garantias honradas pela União, assim como as medidas administrativas e judiciais adotadas para execução das contragarantias, constituindo essas variáveis econômicas de relevo que impactam substancialmente a metodologia de cálculo da dívida consolidada líquida, cujo saldo, em 2016, ultrapassou o limite de $350 \%$ da receita corrente líquida proposto ao Senado Federal, na época, ainda sem aprovação;

c) Auditoria operacional, autuada no TC 011.919/2015-9, com o objetivo de apurar as causas e consequências do aumento da dívida interna federal no período de 2011 a 2014;

d) Auditoria operacional objeto do processo TC 007.722/2015-0, a fim de avaliar o impacto das operações com títulos públicos emitidos diretamente ao BNDES, de 2008 a 2014, nos custos da dívida pública mobiliária federal.

Não obstante o recente ativismo do TCU, Moutinho e Lochagin ${ }^{36}$ constatam que, dada a vultuosidade da dívida pública brasileira e o que ela consome de recursos do orçamento federal, ainda é insuficiente a atenção conferida ao assunto quando se compara o número de auditorias instauradas com o número total de fiscalizações realizadas pelo órgão em um mesmo período.

Por tudo o que foi exposto e considerando o momento de grave crise financeira que assola praticamente todos os entes da federação, não há como os Tribunais de Contas dos Estados e dos Municípios ignorarem a proatividade da Corte de Contas Federal, sendo dever dos seus representantes (conselheiros) fazer uso das competências constitucionais que lhes foram atribuídas, cessando assim a

36 Apesar de os trabalhos terem apresentado constatações importantes, gerado relevante conhecimento do objeto e resultado em importantes determinações e recomendações, a pouca atenção relativa que a Corte de Contas Federal tem dado ao assunto fica patente quando observada a distribuição por área de seus 361 principais trabalhos de fiscalização no período, destacados pelo próprio TCU. Entre as 361, 56 fiscalizações foram realizadas na área de energia - que representa $1,87 \%$ da despesa total fixada na LOA 2018 -, enquanto apenas seis dos principais trabalhos tiveram como objeto a fiscalização da gestão da DPF - cujo refinanciamento pode absorver 32,37\% da despesa fixada na LOA 2018 (LOCHAGIN, Gabriel Loretto e MOUTINHO, Donato Volkers. Controle da gestão da dívida pública federal, cit., p. 76). 
omissão em relação ao controle externo efetivo do endividamento público dos entes subnacionais.

\section{CONSIDERAÇÕES FINAIS}

O trabalho teve como mote defender o uso potencial da competência fiscalizatória dos Tribunais de Contas dos Estados e dos Municípios no âmbito do controle externo do endividamento público dos seus entes.

O controle da dívida pública em uma federação, como é o caso do Estado Brasileiro, requer ainda mais cautela diante das relações constitucionais que se estabelecem entre os três níveis de governo (Federal, Estadual e Municipal), sobretudo aquelas que de alguma forma limitam o grau de autonomia financeira dos entes subnacionais.

Como restou explicitado, o crédito público é um dos mais importantes mecanismos de gestão dos recursos estatais, sendo um instrumento de grande valia para o planejamento e a execução da política financeira, além de apresentar-se como uma das formas pelas quais a entidade subnacional exerce sua autonomia financeira.

Entretanto, como ressaltado ao longo deste trabalho, o grande risco de uma má gestão da dívida pública é que os prejuízos dela advindos podem refletir-se não somente no momento presente, mas também atingir as gerações futuras, sobre as quais recairia a responsabilidade pelo adimplemento do montante devido, o qual foi gerado a partir de uma gestão fiscalmente irresponsável no passado.

É crucial, portanto, que os Tribunais de Contas dos entes subnacionais se apropriem efetivamente das suas funções constitucionais e legais, utilizando-se da notória especialização e do conhecimento acumulado de suas auditorias, visando não apenas o controle dos aspectos formais, mas principalmente apontando para a eficácia, a efetividade, a eficiência e a economicidade no uso dos recursos provenientes do endividamento público.

\section{REFERÊNCIAS}

Livros, dissertações, teses, artigos, manuais e boletins

ANDRADE, Cesar Augusto Seijas de. O controle do endividamento público e a autonomia dos entes da federação. Dissertação (Mestrado) - Faculdade de Direito da Universidade de São Paulo, São Paulo, 2012.

ASSONI FILHO, Sérgio. Empréstimos públicos e sua natureza jurídica. Revista da Faculdade de Direito da Universidade de São Paulo, v. 99, p. 799, 2004.

BRASIL. Operações de Crédito de Estados e Municípios - Manual de Instrução de Pleitos (MIP). Disponível em: https://conteudo.tesouro.gov.br/manuais/mip, diversos acessos. 
BRASIL. Secretaria do Tesouro Nacional. Boletim de Finanças dos Entes Subnacionais. Disponível em: http://www.tesouro.fazenda.gov.br/-/stn-divulga-novoboletim-de-financas-de-estados-e-municipios. Diversos acessos.

CONTI, José Mauricio. Artigos 32 a 39. In: MARTINS, Ives G. S.; NASCIMENTO, Carlos V. (coord.). Comentários à lei de responsabilidade fiscal. 6. ed. São Paulo: Saraiva, 2012.

CONTI, José Mauricio. Federalismo fiscal e fundos de participação. São Paulo: Juarez de Oliveira, 2001.

CONTI, José Mauricio. Tribunais de Contas são os guardiões do dinheiro público. In: CONTI, José Mauricio. Levando o direito financeiro a sério. São Paulo: Blucher, 2016. p. 181-185.

CORIGLIANO, Rogério de Menezes. Empréstimos públicos. Dissertação (Mestrado) - Faculdade de Direito da Universidade de São Paulo, São Paulo, 2003.

GIAMBIAGI, Fábio; ALÉM, Ana Claudia. Finanças públicas: teoria e prática no Brasil. 3. ed. Rio de Janeiro: Elsevier, 2008.

LOCHAGIN, Gabriel Loretto; MOUTINHO, Donato Volkers. Controle da gestão da dívida pública federal. Revista do Mestrado em Direito da Universidade Católica de Brasília (RVMD), Brasília, v. 11, n. 2, p. 45-82, jul./dez. 2017.

LOCHAGIN, Gabriel Loretto. Dívida pública: conceito, tipos e natureza jurídica. In: LOCHAGIN, Gabriel Loretto. Elementos jurídicos da reestruturação internacional da dívida pública. São Paulo: Blucher, 2017. p. 27-68.

LOPREATO, Francisco Luiz Cazeiro. O colapso das finanças estaduais e a crise da federação. São Paulo: Unesp, 2002.

MARTINS, Ives G. S.; NASCIMENTO, Carlos V. (coord.). Comentários à lei de responsabilidade fiscal. 6. ed. São Paulo: Saraiva, 2012.

MUSGRAVE, R.; MUSGRAVE, P. Public finance in theory and practice. Nova Iorque: McGraw Hill, 1980.

PORTUGAL. Tribunal de Contas. Encontro Luso-Brasileiro de Tribunais de Contas realizado em Portugal, no ano de 2003. Disponível em: https://www.tcontas.pt/pt/ publicacoes/outras/enc_luso-brasileiro/enc_luso-brasileiro.pdf.

RIGOLON, Francisco José Zagari; GIAMBIAGI, Fabio. A renegociação das dívidas e regime fiscal dos estados. In: GIAMBIAGI, Fabio; MOREIRA, Maurício Mesquita (org.). A economia brasileira nos anos 90. Rio de Janeiro: Banco Nacional de Desenvolvimento Econômico e Social, 1999. p. 111-144.

TER-MINASSIAN, Teresa; CRAIG, Jon. Control of subnational government borrowing. In: TER-MINASSIAN, Teresa (ed.). Fiscal federalism in theory and practice. Washington: International Monetary Fund, 1997. p. 156-172.

\section{Legislação}

BRASIL. Constituição da República Federativa do Brasil, de 05 de outubro de 1988. Disponível em: http://www.planalto.gov.br, diversos acessos. 
BRASIL. Lei Complementar n. 148, de 25 de novembro de 2014. Altera a Lei Complementar no 101, de 4 de maio de 2000, que estabelece normas de finanças públicas voltadas para a responsabilidade na gestão fiscal; dispõe sobre critérios de indexação dos contratos de refinanciamento da dívida celebrados entre a União, Estados, o Distrito Federal e Municípios; e dá outras providências. Diário Oficial da União, Brasília, 26 nov. 2014.

BRASIL. Lei Complementar n. 101, de 04 de maio de 2000. Disponível em: http:// www.planalto.gov.br/ccivil_03/leis/LCP/Lcp101.htm, diversos acessos.

BRASIL. Lei Federal n. 4.320, de 17 de março de 1964. Disponível em: http://www. planalto.gov.br, diversos acessos.

BRASIL. Lei Federal n. 7.976, de 27 de dezembro de 1989. Disponível em: http://www. planalto.gov.br, diversos acessos.

BRASIL. Lei Federal n. 8.727, de 05 de novembro de 1993. Disponível em: http:// www.planalto.gov.br, diversos acessos.

BRASIL. Lei Federal n. 9.496, de 11 de setembro de 1997. Disponível em: http://www. planalto.gov.br, diversos acessos.

BRASIL. Medida Provisória n. 1.514-1, de 5 de setembro de 1996. Estabelece mecanismos objetivando incentivar a redução da presença do setor público estadual na atividade financeira bancária, dispõe sobre a privatização de instituições financeiras, e dá outras providências. Diário Oficial da União, Brasília, 6 set. 1996.

BRASIL. Medida Provisória n. 1.560-8, de 12 de agosto de 1997. Estabelece critérios para a consolidação, a assunção e o refinanciamento, pela União, da dívida pública mobiliária e outras que especifica, de responsabilidade dos Estados e do Distrito Federal. Diário Oficial da União, Brasília, 13 ago. 1997.

BRASIL. SENADO. Resolução n. 40, de 2001. Disponível em: http://www2.camara. leg.br/legin/fed/ressen/2001/resolucao-40-20-dezembro-2001-29320 -normaatualizadapl.html, diversos acessos. BRASIL. SENADO. Resolução n. 43, de 2001. Disponível em: http://www2.camara.leg.br/legin/fed/ressen/2001/resolucao-43-26-dezembro-200129342-normaatualizada-pl.html, diversos acessos.

\section{Jurisprudência}

BRASIL. Acórdão 571/2017, Processo n. TC 033.619/2016, Relator Ministro Aroldo Cedraz, Plenário, Ata n. 10/2017. Data da Sessão: 29/03/2017 - Ordinária.

BRASIL. Tribunal de Contas da União. Acórdão 1776/2012, Processo n. TC 021.465/2010-0, Relator Walton Alencar Rodrigues, Plenário. Ata n. 26/2012. Data da Sessão: 11/07/2012 - Ordinária. 
